\title{
Thermal Conductivity of Tooth Structure, Dental Cements, and Amalgam
}

\author{
R. G. CRAIG and F. A. PEYTON \\ School of Dentistry, University of Michigan, Ann Arbor, Michigan
}

The thermal conductivity of human dentin has been reported by Lisanti and Zander, ${ }^{1}$ Simeral, ${ }^{2}$ Phillips, Reinking, and Phillips, ${ }^{3}$ and Soyenkoff and Okun ${ }^{4}$ to be $2.29 \times 10^{-3}$, $2.35 \times 10^{-3}, 0.257 \times 10^{-3}$, and $0.96-1.07 \times 10^{-3} \mathrm{cal} / \mathrm{sec} / \mathrm{cm}^{2} /{ }^{\circ} \mathrm{C} / \mathrm{cm}$, respectively. The thermal conductivity of human enamel has been reported by Soyenkoff and Okun ${ }^{3}$ to be $1.55 \times 10^{-3}$.

More limited data are available for zinc phosphate and silicate cements. Simeral ${ }^{2}$ reported values of $2.81 \times 10^{-3}$ for zinc phosphate and $2.00 \times 10^{-3}$ for silicate cements. Phillips and co-workers ${ }^{3,5}$ at different times listed the thermal conductivity of zinc phosphate cement to be $3.91-5.37 \times 10^{-3}$ and $0.311-0.388 \times 10^{-3} \mathrm{cal} / \mathrm{sec} / \mathrm{cm}^{2} /{ }^{\circ} \mathrm{C} / \mathrm{cm}$, which represents the centimeter, gram, second (c.g.s.) units of measurement. Silicate cement was found to have a thermal conductivity of $0.458 \times 10^{-3}$ c.g.s. units. ${ }^{5} \mathrm{~A}$ survey of the dental literature revealed that no values have been reported for amalgam.

All the literature values indicated that dentin, enamel, zinc phosphate cements, and silicate cements were good thermal insulators, although the numerical values for the various materials often disagreed by a factor of 10 . It was the purpose of this investigation to establish more accurately the thermal conductivity of tooth structure and dental cements, as well as to determine a value for dental amalgam.

\section{MATERIALS AND METHODS}

Specimen preparation.-Dentin and enamel specimens were cut from human teeth by means of a diamond-core drill mounted on a jeweler's lathe. The cylindrical blanks obtained were held in the lathe by a chuck, and the sides of the cylinder were cut down by a tungsten carbide tool. The dentin specimens were cut to a diameter of 0.234 inch $\left(15 / 64^{\prime \prime}\right)$ and the enamel specimens to a diameter of 0.156 inch $\left(5 / 32^{\prime \prime}\right)$. These finished cylinders were then placed in appropriate collets in the lathe and the ends ground flat and parallel by a grinding attachment and an India stone. The thickness of the enamel specimens was 0.030 inch, and those for dentin varied from 0.045 to 0.060 inch.

The zinc phosphate* and silicatef cement specimens were prepared by placing the mixed cement in a split stainless-steel mold, which was 0.234 inch in diameter and

This study was supported in part by U.S.P.H.S. research grant D-462 from the National Institute of Dental Research, National Institutes of Health, and the University of Michigan.

Received for publication May 12, 1960.

* The L. D. Caulk Company, Tenacin Cement.

$\dagger$ The S. S. White Dental Manufacturing Co., Improved Filling Porcelain. 
0.12 inch thick. The zinc phosphate inlay seating consistency mix contained $1.1 \mathrm{gm}$. of powder for $0.5 \mathrm{cc}$. of liquid, and thick cement base mix contained $1.85 \mathrm{gm}$. of powder for $0.5 \mathrm{cc}$. of cement liquid. The consistency of the silicate cement samples was $1.43 \mathrm{gm}$. of powder for $0.4 \mathrm{cc}$. of cement liquid. After preparation, the samples were stored in distilled water until the thermal conductivity was determined, which varied from 1 to 7 days after preparation.

The amalgam specimens were condensed in stainless-steel molds and had dimensions of 0.234 inch in diameter and a thickness of either 0.06 or 0.12 inch. The manufacturer's* recommended proportions were used, and normal (8-10-lb.), heavy (10-12-lb.), or light (4-8-lb.) condensation pressure on a 2-mm. condenser was used. The surfaces of most of the specimens were finished by lightly polishing with $600 \mathrm{~A}$ silicon carbide paper. A few of the specimens were used with the surface finish obtained by trimming only with a razor blade.

Thermal conductivity equipment.-The thermal conductivity was determined with equipment which was essentially a modification of that reported by Lisanti and Zander. ${ }^{1}$ The specimens were placed between two pure copper rods and were held firmly in position by the action of a spring. The copper rods used were the same diameter as the specimens, and each was $6.5 \mathrm{~cm}$. long. One end of the rod was ground flat with the jeweler's lathe, and the other end was threaded so that it could be screwed into the heating and cooling unit. Minute holes were drilled in the rods $1 \mathrm{~mm}$. from the sample end and at intervals of $1 \mathrm{~cm}$. Thus each rod had seven holes spaced at $1 \mathrm{~cm}$. intervals into which were inserted copper-constantan thermocouples made from 28-gauge wire. The threaded end of one rod was screwed into a copper block, which could be electrically heated by current from a 6-volt storage battery. The other rod was screwed into another copper block, which was cooled by circulating water. The cooling water was taken from a thermostatically controlled storage tank which maintained a constant pressure.

Thermal conductivity measurement.-The rod assembly, including supports, was contained in a plywood box, having a 16-inch edge length. The lower portion of the box was packed with glass-wool insulation, while sections of polystyrene foam were used in the upper parts of the box. The foam sections could be easily removed to allow for changing thermal conductivity samples.

The thermal conductivity sample was placed between the copper rods, using a film of glycerine on each surface to insure adequate contact. The entire system was allowed to reach a steady-state condition, where the heat flow in equaled the heat flow out. Under these conditions, the temperature of each position remained constant with time. Then the temperature at the various positions along the copper rods was measured by the thermocouples and a potentiometer. $t$ The potentiometer had a sensitive scale from 0 to 16 millivolts, graduated in 0.01 millivolt. The temperature could be measured to $\pm 0.05^{\circ} \mathrm{C}$. with this equipment. An extrapolation of the plot of the temperature against distance along the copper rods permitted the determination of the surface temperature on the hot and cold sides of the conductivity specimen.

In order to establish whether or not steady-state conditions had been attained, which took from 16 to 20 hours, the temperature of the thermocouple positions was determined at 1-2-hour intervals. When two successive runs gave the same temperature

* The S. S. White Dental Manufacturing Co.

$\dagger$ Leeds and Northrup Co. 
values, it was assumed that the system had reached a steady state. After steady state had been established, a minimum of four separate determinations, at 1-hour intervals, was made of the thermal conductivity of each of the specimens.

Thermal conductivity calculation.-Under steady-state conditions the quantity of heat flowing through the copper rod, $q_{1}$, is represented by equation, (1),

$$
q_{1}=k_{1} A_{1}\left(\frac{\Delta t_{1}}{X_{1}}\right)
$$

where $k_{1}$ is the thermal conductivity of copper, $A_{1}$ is the area of the copper rods, $\Delta t_{1}$ is the change in temperature along the copper rod, and $X_{1}$ is the distance over which this temperature change occurs. The quantity of heat flowing through the specimen may be represented by $q_{2}=U \Delta t_{2,3}$, where $U$ is equal to the following expression:

$$
U=\frac{1}{\left(X_{2} / k_{2} A_{2}\right)+\left(X_{3} / k_{3} A_{3}\right)} .
$$

The terms $X_{2}$ and $X_{3}$ are the sample and glycerine thicknesses, respectively, while $k_{2}$ and $k_{3}$ are the thermal conductivities of the sample and glycerine, and $A_{2}$ and $A_{3}$ are the areas of the sample and glycerine film, respectively. The term $\Delta t_{2,3}$ represents the temperature drop across the sample and the glycerine films.

The qualities $q_{1}$ and $q_{2}$ may be equated under conditions of steady state, as indicated in equation (3),

$$
k_{1} A_{1}\left(\frac{\Delta t_{1}}{X_{1}}\right)=\frac{\Delta t_{2,3}}{\left(X_{2} / k_{2}\right.} \frac{\left.A_{2}\right)+\left(X_{3} / k_{3} A_{3}\right)}{.} .
$$

All the quantities in equation (3) are known, except $k_{2}$, the thermal conductivity of the specimen, and thus it may be calculated. Equation (3) has been simplified for ease of calculating the thermal conductivities of unknown materials, as shown in equation (4):

$$
k_{2}=\frac{k_{1} k_{3} d_{1}^{2}\left(X_{2} \text { slope }_{1}\right)}{k_{3} d_{2}^{2}\left(\Delta t_{2,3}\right)-k_{1} d_{3}^{2} X_{3}\left(\text { slope }_{1}\right)} .
$$

For the sake of simplicity, the squares of the diameters of the rods, specimen, and glycerine film were used, rather than the areas. Likewise, the slope of the temperature versus distance plot along the copper rod on the cold side was substituted for $t_{1} / X_{1}$. If the average of the slope on the hot and cold slides were used, this would increase the thermal conductivity of dentin from the reported value of $1.4 \times 10^{-3}$ to $1.7 \times 10^{-3}$ $\mathrm{cal} / \mathrm{sec} / \mathrm{cm}^{2} /{ }^{\circ} \mathrm{C} / \mathrm{cm}$. For each thermal conductivity measurement, the terms in parentheses were required. The sample thickness, the slope of the temperature versus distance plot, and the temperature drop across the specimen, therefore, were needed in order to calculate the thermal conductivity.

The right-hand term in the denominator of equation (4) is the correction for the glycerine film on each side of the specimen. Values for $X_{3}$, the double film thickness, were determined by using a copper specimen and were checked by using a glass* specimen approximately the thickness of the unknown specimen. The glycerine film

* Corning Glass Company, Pyrex glass. 
thickness, using the 0.234 -inch diameter copper rods, was $20 \mu$ for all samples from 0.045 to 0.12 inch thick. The 0.156 -inch diameter copper rods were used only for the smaller enamel specimens, and a film thickness of $50 \mu$ was obtained. This increase in film thickness presumably was a result of using copper rods $60 \mathrm{~mm}$. in length rather than the usual length of $65 \mathrm{~mm}$. A significantly lower spring pressure was exerted on the samples when the shorter copper rods were used, and therefore a thicker glycerine film was observed.

Glass* specimens of various thickness, with a thermal conductivity of $2.7 \times 10^{-3}$ $\mathrm{cal} / \mathrm{sec} / \mathrm{cm}^{2} /{ }^{\circ} \mathrm{C} / \mathrm{cm}$ were used as standards throughout this study, and ten standardization runs were made. A maximum error of 3 per cent was observed in the standardization runs. Seven of the ten standardization runs were within 1.5 per cent of the theoretical value $\left( \pm 0.03 \times 10^{-3}\right.$ c.g.s. units $)$. It was observed that slightly better

TABLE 1

Thermal CONDUCTIVITy OF DENTIN AND ENAMEL*

\begin{tabular}{|c|c|c|c|}
\hline \multirow[b]{2}{*}{ SAMPLE } & \multicolumn{2}{|c|}{ DENTIN } & \multirow{2}{*}{$\begin{array}{l}\text { ENAMEL } \\
\text { Parallel } \\
\text { to Rods } \\
\left(K \times 10^{3}\right)\end{array}$} \\
\hline & $\begin{array}{l}\text { Parallel } \\
\text { to Tubules } \\
\left(K \times 10^{3}\right)\end{array}$ & $\begin{array}{l}\text { Perpendicular } \\
\text { to Tubules } \\
\left(K \times 10^{z}\right)\end{array}$ & \\
\hline $\begin{array}{l}1 \ldots \ldots \\
2 \ldots \ldots \\
3 \ldots \ldots \\
4 \ldots \ldots \\
5 \ldots \ldots \\
6 \ldots \ldots \\
7 \ldots \ldots \\
8 \ldots \ldots\end{array}$ & $\begin{array}{l}1.43 \pm 0.03 \\
1.53 \pm 0.02 \\
1.40 \pm 0.04 \\
1.31 \pm 0.03 \\
1.40 \pm 0.04 \\
1.32 \pm 0.05 \\
1.25 \pm 0.03 \\
1.30 \pm 0.04\end{array}$ & $\begin{array}{c}1.45 \pm 0.04 \\
1.65 \pm 0.04 \\
1.12 \pm 0.02 \\
1.25 \pm 0.03 \\
1.54 \pm 0.05 \\
1.38 \pm 0.03 \\
1.34 \pm 0.04 \\
\ldots \ldots \ldots \ldots\end{array}$ & $\begin{array}{c}2.19 \pm 0.04 \\
2.20 \pm 0.06 \\
2.16 \pm 0.06 \\
2.10 \pm 0.07 \\
2.55 \pm 0.04 \\
2.10 \pm 0.03 \\
2.29 \pm 0.09 \\
\ldots \ldots \ldots \ldots\end{array}$ \\
\hline Mean. . & $1.36 \pm 0.07 \times 10^{-3}$ & $1.39 \pm 0.12 \times 10^{-3}$ & $2.23 \pm 0.11 \times 10^{-3}$ \\
\hline
\end{tabular}

* Determined at an average temperature of $50^{\circ} \mathrm{C}$.; reported in cal $/ \mathrm{sec} / \mathrm{cm}^{2} /{ }^{\circ} \mathrm{C} / \mathrm{cm}$.

thermal conductivity values for glass were obtained if the slope of the temperature versus distance plot on the cold side of the specimen was used. The slope on the hot side was always slightly higher and, if averaged with the slope on the cold side, gave somewhat higher thermal conductivity values. The higher rate of change of temperature on the hot side of the sample was presumably due to greater heat loss by radiation, since the rod temperature was approximately $45^{\circ} \mathrm{C}$. higher than the ambient temperature of the insulation. Radiation effects may be neglected in the case of the copper rod on the cold side, since the temperature was within a few degrees of the ambient temperature.

\section{RESULTS}

The thermal conductivity values for human dentin and enamel are listed in Table 1. Dentin specimens having the tubule direction parallel to the heat flow resulted in an average thermal conductivity for eight samples of $1.36 \times 10^{-3} \mathrm{cal} / \mathrm{sec} / \mathrm{cm}^{2} /{ }^{\circ} \mathrm{C} / \mathrm{cm}$ and an average deviation from the mean of $\pm 0.07 \times 10^{-3}$. Dentin samples with the tubule direction generally perpendicular to the heat flow had an average value of

* Corning Glass Company, Pyrex glass. 
$1.39 \pm 0.12 \times 10^{-3}$ c.g.s. units. These data show that tubule direction does not influence the thermal conductivity of dentin.

Human enamel had a higher thermal conductivity than dentin, with values ranging from 2.10 to $2.55 \times 10^{-3}$ c.g.s. units. The mean value for enamel with the rod direction parallel to the heat flow was $2.23 \pm 0.11 \times 10^{3}$ c.g.s. units. It should be noted that the average deviation from the mean for a single sample of dentin or enamel was less than the average deviation calculated by averaging the thermal conductivities of all samples of a similar type. This suggests an actual variation in the thermal conductivity from one tooth to another or possibly variations in sample preparation.

The zinc phosphate cement specimens, prepared from an inlay or crown-and-bridge consistency mix and measured in an essentially wet condition, resulted in a mean value of $2.5 \times 10^{-3} \mathrm{cal} / \mathrm{sec} / \mathrm{cm}^{2} /{ }^{\circ} \mathrm{C} / \mathrm{cm}$ and an average deviation from the mean of $\pm 0.3 \times 10^{-3}$ c.g.s. units, as shown in Table 2 . The samples prepared from the base-

TABLE 2

Thermal Conductivity of Zinc Phosphate and Silicate Cements

\begin{tabular}{|c|c|c|c|c|c|}
\hline \multirow{2}{*}{ SAMPLE } & \multicolumn{2}{|c|}{ Zinc Phosphate Chment* } & \multicolumn{3}{|c|}{ Silicate Cement $\dagger$} \\
\hline & $\begin{array}{l}\text { Inlay Mix } \$ \\
\left(K \times 10^{3}\right)\end{array}$ & $\begin{array}{c}\text { Base Mix } \S \\
\left(K \times 10^{3}\right)\end{array}$ & $\begin{array}{l}\text { Days after } \\
\text { Mix }\end{array}$ & $\begin{array}{l}\text { 1st Day of Run } \\
\left(K \times 10^{3}\right)\end{array}$ & $\begin{array}{l}\text { 2d Day of Run } \\
\left(K \times 10^{3}\right)\end{array}$ \\
\hline $\begin{array}{l}1 \ldots \\
2 \ldots \\
3 \ldots \\
4 \ldots \\
5 \ldots \\
6 \ldots\end{array}$ & $\begin{array}{l}1.93 \pm 0.09 \\
3.10 \pm 0.10 \\
2.65 \pm 0.10 \\
2.54 \pm 0.06 \\
2.53 \pm 0.09 \\
2.14 \pm 0.07\end{array}$ & $\begin{array}{l}3.72 \pm 0.10 \\
3.46 \pm 0.01 \\
2.91 \pm 0.02 \\
2.89 \pm 0.03 \\
2.80 \pm 0.09 \\
2.56 \pm 0.09\end{array}$ & $\begin{array}{l}1 \\
2 \\
3 \\
5 \\
5 \\
7\end{array}$ & $\begin{array}{l}1.90 \pm 0.03 \\
1.76 \pm 0.04 \\
1.57 \pm 0.02 \\
1.70 \pm 0.05 \\
2.02 \pm 0.01 \\
2.20 \pm 0.06\end{array}$ & $\begin{array}{l}1.82 \pm 0.04 \\
1.57 \pm 0.06 \\
1.73 \pm 0.03 \\
1.75 \pm 0.03 \\
1.81 \pm 0.07 \\
2.03 \pm 0.02\end{array}$ \\
\hline Mean. . & $2.5 \pm 0.3 \times 10^{-3}$ & $3.1 \pm 0.3 \times 10^{-3}$ & $\ldots$ & $1.9 \pm 0.2 \times 10^{-3}$ & $1.8 \pm 0.1 \times 10^{-3}$ \\
\hline
\end{tabular}

* Determined at an average temperature of $55^{\circ} \mathrm{C}$, reported in $\mathrm{cal} / \mathrm{sec} / \mathrm{cm}^{2} /{ }^{\circ} \mathrm{C} / \mathrm{cm}$.

$\dagger$ Determined at an average temperature of $45^{\circ} \mathrm{C}$, reported in cal $/ \mathrm{sec} / \mathrm{cm}^{2} /{ }^{\circ} \mathrm{C} / \mathrm{cm}$.

$\$ 1.1 \mathrm{gm}$. powder to $0.5 \mathrm{cc}$. cement liquid.

$\$ 1.85 \mathrm{gm}$. powder to $0.5 \mathrm{cc}$. cement liquid.

consistency mixes had an average value of $3.1 \times 10^{-3}$ c.g.s. units. Since the average deviation from the mean was again $\pm 0.3 \times 10^{-3}$ c.g.s. units, the data indicate only a slight difference between the thermal conductivity of inlay and base consistency mixes of zinc phosphate cements. Again, less variation was found between different runs from a single sample than between different samples.

The thermal conductivities of the silicate cement specimens also are listed in Table 2. Two values are given for each sample, the first representing the thermal conductivity during the first day in the thermal conductivity apparatus and the second value giving the conductivity during the second day. The average values of $1.9 \pm 0.2 \times 10^{-3}$ $\mathrm{cal} / \mathrm{sec} / \mathrm{cm}^{2} /{ }^{\circ} \mathrm{C} / \mathrm{cm}$ for the first day and $1.8 \pm 0.1 \times 10^{-3}$ c.g.s. units for the second day illustrate that little, if any, dehydration toot place under the experimental conditions. The thermal conductivity of the silicate cement specimens was determined $1,2,3,5$, and 7 days after preparation, and no trend was observed, possibly because of the variations obtained for different samples.

Dental amalgam was found to have an average thermal conductivity of $5.4 \times 10^{-2}$ $\mathrm{cal} / \mathrm{sec} / \mathrm{cm}^{2} /{ }^{\circ} \mathrm{C} / \mathrm{cm}$, as reported in Table 3 . Considerable variation was observed from 
sample to sample, as indicated by figures ranging from 4.43 to $6.87 \times 10^{-2}$ c.g.s. units. Unfortunately, no trend in the figures could be attributed to condensation pressure, sample finish, amalgam alloy, or mercury content of the amalgam samples, since variations between samples were too large. Finished samples prepared by using normal condensation pressure had thermal conductivities from 4.43 to $6.87 \times 10^{-2} \mathrm{cal} / \mathrm{sec} /$ $\mathrm{cm}^{2} /{ }^{\circ} \mathrm{C} / \mathrm{cm}$; those prepared with heavy condensation pressure varied from 5.05 to $6.40 \times 10^{-2}$; and those condensed with light pressure ranged from 6.10 to $6.23 \times 10^{-2}$ c.g.s. units.

It might be expected that samples having the highest mercury content would have the lowest thermal conductivity, but sample 13, a lightly condensed specimen with

TABLE 3

Thermal Conductivity of Dental AMalgam*

\begin{tabular}{|c|c|c|c|c|}
\hline Sample $f$ & $\begin{array}{l}\text { Condensation } \\
\text { Pressure }\end{array}$ & $\begin{array}{l}\text { Sample Surface } \\
\text { Finish }\end{array}$ & $\begin{array}{c}\text { Mercury } \\
\text { Content } \\
\text { (Per Cent) }\end{array}$ & $K \times 10^{2}$ \\
\hline 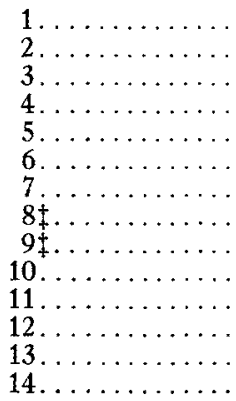 & $\begin{array}{l}\text { Normal } \\
\text { Normal } \\
\text { Normal } \\
\text { Normal } \\
\text { Normal } \\
\text { Normal } \\
\text { Normal } \\
\text { Normal } \\
\text { Normal } \\
\text { Heavy } \\
\text { Heavy } \\
\text { Heavy } \\
\text { Light } \\
\text { Light }\end{array}$ & $\begin{array}{l}\text { Unfinished } \\
\text { Unfinished } \\
\text { Unfinished } \\
\text { Finished } \\
\text { Finished } \\
\text { Finished } \\
\text { Finished } \\
\text { Finished } \\
\text { Finished } \\
\text { Finished } \\
\text { Finished } \\
\text { Finished } \\
\text { Finished } \\
\text { Finished }\end{array}$ & $\begin{array}{c}45.2 \\
\ldots . \ldots \ldots \\
47.0 \\
46.4 \\
\ldots \ldots \ldots \ldots \\
\ldots \ldots \ldots \\
\ldots \ldots \ldots \\
43.6 \\
42.8 \\
43.3 \\
\ldots \ldots \ldots \\
\ldots \\
47.8 \\
\ldots \ldots \ldots\end{array}$ & $\begin{array}{l}4.46 \pm 0.06 \\
4.64 \pm 0.05 \\
5.52 \pm 0.06 \\
5.40 \pm 0.06 \\
4.43 \pm 0.12 \\
4.47 \pm 0.13 \\
4.54 \pm 0.08 \\
6.87 \pm 0.14 \\
5.35 \pm 0.15 \\
6.40 \pm 0.14 \\
6.33 \pm 0.06 \\
5.05 \pm 0.07 \\
6.10 \pm 0.05 \\
6.23 \pm 0.10\end{array}$ \\
\hline Mean. ... & & & $\ldots \ldots \ldots \ldots$ & $5.4 \pm 0.7 \times 10^{-2}$ \\
\hline
\end{tabular}

* Determined at an average temperature of $36^{\circ} \mathrm{C}$., in cal $/ \mathrm{sec} / \mathrm{cm}^{2} /{ }^{\circ} \mathrm{C} / \mathrm{cm}$.

$\dagger$ All samples except 8 and 9 were prepared from S. S. White Sigrens.

$¥$ Prepared from S. S. White New True Dental Alloy, fine cut.

the highest mercury content of 47.8 per cent, had a relatively high conductivity of $6.10 \times 10^{-2}$ c.g.s. units. Also sample 9, which had the lowest mercury content of 42.8 per cent, resulted in a lower conductivity value of only $5.35 \times 10^{-2}$ c.g.s. units. Table 3 includes other examples of the lack of correlation of manipulation of amalgam with thermal conductivity.

\section{DISCUSSION}

A summary of the thermal conductivity for dentin, enamel, zinc phosphate cement, silicate cement, and amalgam reported by various investigators is presented in Table 4 . The values are listed chronologically for each material.

The figures listed for human dentin can be divided into three groups. The average thermal conductivity of $2.29 \times 10^{-3}$ and $2.35 \times 10^{-3} \mathrm{cal} / \mathrm{sec} / \mathrm{cm}^{2} /{ }^{\circ} \mathrm{C} / \mathrm{cm}$ reported by Lisanti and Zander $^{1}$ and Simeral, ${ }^{2}$ respectively, are in close agreement. These results are nearly twice the values of $1.35-1.39 \times 10^{-3}$ found in this research with essentially the same procedures. The principal difference in their procedure was the use of the average of the slopes of the temperature versus distance plot for the hot and cold 
copper rod in the thermal conductivity calculation, which would result in higher values. Improvement in sample preparation in the present study may also account for the difference in results.

The figure of $0.257 \times 10^{-3}$ reported by Phillips and co-workers ${ }^{5}$ is only one-fifth the value found in this study. This value, as well as their figures for zinc phosphate and silicate cements, is very low, possibly because of their method of measurement.

The thermal conductivities of dentin and enamel by Soyenkoff and Okun ${ }^{4}$ were in reasonable agreement with the corresponding values reported in this study. The difference probably represents variations in procedure and sample preparation, particularly in the case of enamel. It should be noted that values for porcelain vary from

TABLE 4

COMPARISON OF Thermal. CONDUCtivities With ThOSE RePORTED IN THE Literature

\begin{tabular}{|c|c|c|c|}
\hline Material & $\begin{array}{c}\text { Thermal } \\
\text { Conductivity } \\
\text { (Cal/Sec/ } \mathrm{Cm}^{2} / \\
\left.{ }^{\circ} \mathrm{C} / \mathrm{Cm}\right)\end{array}$ & $\begin{array}{c}\text { Temperature } \\
\left({ }^{\circ} \mathrm{C} .\right)\end{array}$ & Source \\
\hline 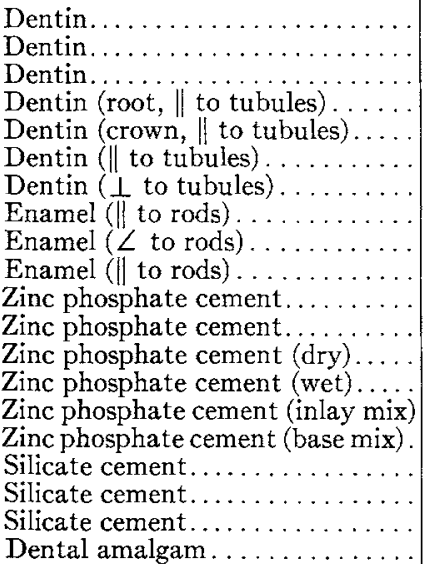 & $\begin{array}{l}2.29 \times 10^{-3} \\
2.35 \times 10^{-3} \\
0.257 \times 10^{-3} \\
0.96 \times 10^{-3} \\
1.07 \times 10^{-3} \\
1.36 \times 10^{-3} \\
1.39 \times 10^{-3} \\
1.55 \times 10^{-3} \\
1.56 \times 10^{-3} \\
2.23 \times 10^{-3} \\
2.81 \times 10^{-3} \\
3.91-5.39 \times 10^{-3} \\
0.31 \times 10^{-3} \\
0.35 \times 10^{-3} \\
2.5 \times 10^{-3} \\
3.1 \times 10^{-3} \\
2.00 \times 10^{-3} \\
0.46 \times 10^{-3} \\
1.78-1.86 \times 10^{-3} \\
5.4 \times 10^{-2}\end{array}$ & $\begin{array}{l}40-90 \\
\ldots \ldots \\
\ldots \ldots \\
29 \\
29 \\
50 \\
50 \\
26-29 \\
26-29 \\
\quad 50 \\
\ldots \ldots \\
\ldots \ldots \\
\ldots \ldots \\
\ldots \ldots \\
\quad 55 \\
\quad 55 \\
\ldots \ldots \\
\ldots \ldots \\
45 \\
36\end{array}$ & $\begin{array}{l}\text { Lisanti and Zander (Ref. 1) } \\
\text { Simeral (Ref. 2) } \\
\text { Phillips and co-workers (Ref. 5) } \\
\text { Soyenkoff and Okun (Ref. 4) } \\
\text { Soyenkoff and Okun (Ref. 4) } \\
\text { Craig and Peyton } \\
\text { Craig and Peyton } \\
\text { Soyenkoff and Okun (Ref. 4) } \\
\text { Soyenkoff and Okun (Ref. 4) } \\
\text { Craig and Peyton } \\
\text { Simeral (Ref. 2) } \\
\text { Phillips and co-workers (Ref. 3) } \\
\text { Phillips and co-workers (Ref. 5) } \\
\text { Phillips and co-workers (Ref. 5) } \\
\text { Craig and Peyton } \\
\text { Craig and Peyton } \\
\text { Simeral (Ref. 2) } \\
\text { Phillips and co-workers (Ref. 5) } \\
\text { Craig and Peyton } \\
\text { Craig and Peyton }\end{array}$ \\
\hline
\end{tabular}

1.9 to $4.7 \times 10^{-3}$, with most of the values near $2.5 \times 10^{-3}$ c.g.s. units. These values are close to those reported for dentin and enamel. The lower thermal conductivity of dentin compared with enamel is possibly a reflection of the larger amount of organic matrix present in the dentin.

The thermal conductivities of zinc phosphate and silicate cements reported by Simeral $^{2}$ of $2.81 \times 10^{-3}$ and $2.00 \times 10^{-3}$ c.g.s. units, respectively, were in good agreement with the values of $2.5-3.1 \times 10^{-3}$ and $1.78-1.86 \times 10^{-3} \mathrm{c.g} .5$. units found in this investigation. The early figures reported by Phillips $^{3}$ for zinc phosphate cement were in reasonable agreement with the previous values, but a later paper ${ }^{5}$ lists the thermal conductivity as $0.31-0.35 \times 10^{-3} \mathrm{c.g}$.s. units, or about one-tenth the early values. Likewise, the value reported by Phillips $^{5}$ of $0.46 \times 10^{-3}$ for silicate cement is much lower than those reported by the other authors.

The thermal conductivity of dental amalgam cannot be compared because of lack of literature values. It is interesting, however, that an amalgam containing possibly 45 per cent mercury, 39 per cent silver, 14 per cent tin, and 2 per cent copper, which 
have individual conductivities of $0.019,1.00,0.14$, and $0.92 \mathrm{cal} / \mathrm{sec} / \mathrm{cm}^{2} /{ }^{\circ} \mathrm{C} / \mathrm{cm}$, respectively, has a thermal conductivity of 0.054 c.g.s. units. The presence of mercury or amalgams, therefore, has a pronounced effect on the thermal conductivity of a finished amalgam restoration. The conductivity of the amalgam is only three times that of mercury, which is a relatively poor metallic thermal conductor.

The thermal conductivity of dental amalgam, therefore, is low compared with other restorative dental materials such as pure gold, $90 \mathrm{Au}-10 \mathrm{Cu}$, and $80 \mathrm{Au}-20 \mathrm{Cu}$, which have thermal conductivities of approximately $0.74,0.29$, and $0.17 \mathrm{cal} / \mathrm{sec} / \mathrm{cm}^{2} /$ ${ }^{\circ} \mathrm{C} / \mathrm{cm}$, respectively. The conductivity of dental amalgam still is high compared with zinc phosphate and silicate cements, which have conductivities comparable to human tooth structure.

Thus it may be concluded that zinc phosphate and silicate cements are adequate thermal insulators in replacing lost tooth tissue. It also appears that a zinc phosphate cement base essentially replaces dentin in a deep-cavity preparation with respect to thermal insulation of the dental pulp. Although amalgams have considerably lower thermal conductivities than dental golds, a cement base would still be recommended in a deep-cavity preparation.

It should be emphasized that the numerical thermal conductivity values are independent of sample thickness, but the effectiveness of a cement base as an insulating medium is directly proportional to the thickness of the base. This fact should be considered in the placement of a cement base.

\section{SUMMARY}

The thermal conductivity of human dentin, enamel, zinc phosphate cement, silicate cement, and dental amalgram has been determined by using an improved steady-state procedure.

The average thermal conductivity of dentin was $1.36-1.39 \times 10^{-3} \mathrm{cal} / \mathrm{sec} / \mathrm{cm}^{2} /{ }^{\circ} \mathrm{C}$ / $\mathrm{cm}$, which was lower than the value of $2.23 \times 10^{-3}$ for human enamel.

Zinc phosphate and silicate cements had conductivities of $2.5-3.1 \times 10^{-3}$ and 1.78 $1.86 \times 10^{-3} \mathrm{cal} / \mathrm{sec} / \mathrm{cm}^{2} /{ }^{\circ} \mathrm{C} / \mathrm{cm}$, respectively. These values approximate the value for tooth structure and are in the range of good thermal insulators.

Dental amalgam had an average conductivity of $5.4 \times 10^{-2} \mathrm{cal} / \mathrm{sec} / \mathrm{cm}^{2} /{ }^{\circ} \mathrm{C} / \mathrm{cm}$, which places it as a relatively poor insulator compared with tooth structure or dental cements, but a relatively good insulator compared with dental gold alloys.

The authors gratefully acknowledge the assistance of I. Ibrahim, D. W. Johnson, R. G. Smith, and T. F. Peyton in the collection of the data.

\section{REFERENCES}

1. Lisantr, V. F., and Zander, H. A. Thermal Conductivity of Dentin, J. D. Res., 29:493, 1950.

2. Stmeral, W. G. Thermal Conductivity of Dental Materials, Microfilm of papers presented at the Annual I.A.D.R. Dental Materials Group Meeting, March 17-18, 1951, J. D. Res., $30: 499,1951$ (abstr.).

3. Phillips, R. W., Reinking, R. H., and Phillips, L. J. Thermal Conductivity of Dental Cement, J. D. Res, $33: 511,1954$.

4. Soyenkofr, B. C., and Orun, J. H. Thermal Conductivity Measurements of Dental Tissues with the Aid of Thermistors, J.A.D.A., $57: 23,1958$.

5. Phillips, R. W., Johnson, R. J., and Phillips, L. J. An Improved Method for Measuring the Coefficient of Thermal Conductivity of Dental Cement, J.A.D.A., 53:577, 1956. 